\title{
Comparison of metropolitan cities for mortality rates attributed to ambient air pollution using the AirQ model
}

\author{
Ahmet Cihat Kahraman ${ }^{1}$ (D) . Nüket Sivri ${ }^{2}$
}

Received: 24 August 2021 / Accepted: 21 December 2021 / Published online: 29 January 2022

(c) The Author(s), under exclusive licence to Springer-Verlag GmbH Germany, part of Springer Nature 2021

\begin{abstract}
In the present study, the air pollution dynamics of the metropolitan cities of Balıkesir, Bursa, Istanbul, Kocaeli, Sakarya and Tekirdağ in the Marmara Region, which is the geographical region with the highest urban and industrial activity in Turkey, were examined for the time period between 2016 and 2019. Annual changes in the cities in terms of air pollution, which was examined with a focus on the $\mathrm{PM}_{2.5}$ parameter as indicated by United Nations (UN) Sustainable Development Goals (SDGs); differences in the cities by years; and the seasonal changes in air pollution in the cities were investigated. Additionally, mortality rates attributed to air pollution were calculated with the AirQ + software based on integrated exposure-response function recommended by the World Health Organization (WHO) and the UN using city-scale statistics of fatal disease cases that can be attributed to air pollution. It was determined that all cities in the Marmara Region study area exceeded the limit $\mathrm{PM}_{2.5}$ values specified by the European Union (EU) in the years 2016, 2017 and 2018 while only Kocaeli and Tekirdağ were below the limit values in 2019. The limit values specified by the WHO were exceeded in all cities in each year. A total of 46,920 premature deaths attributed to the exceedance of WHO limit values were calculated for the years 2016, 2017, 2018 and 2019 with $11,895,13,853,11,748$ and 9,429, respectively. Determining national limit values for the $\mathrm{PM}_{2.5}$ parameter, which is among the most important factors of air pollution, and monitoring it in a sustainable manner using a sufficient number of well-equipped stations is of great importance. This way, national, regional and urban action plans regarding the impact of air pollution on human health, as indicated by UN SDGs, can be prepared.
\end{abstract}

Keywords Air pollution $\cdot$ Particulate matter $\cdot$ Mortality $\cdot$ SDG $\cdot$ AirQ $\cdot$ Turkey

\section{Introduction}

Air pollution is of vital importance for many areas including energy, climate, transportation, trade, agriculture and biological diversity. In addition to posing risks for the environment, economy and food safety, its impact on human health is also critical (Pope et al., 1995; Rafaj et al., 2018). It has been revealed through the epidemiological studies conducted since the 1980s that the relationship between particulate pollution and mortality is consistent. In these studies, it was

Communicated by Lotfi Aleya.

Ahmet Cihat Kahraman

acihatkahraman@gmail.com

1 Institute of Graduate Studies, Istanbul University-Cerrahpasa (IUC), 34320, Avc1lar, Istanbul, Turkey

2 Faculty of Engineering, Department of Environmental Engineering, IUC, 34320, Avcılar, Istanbul, Turkey reported that air pollution at high concentrations has caused the death of hundreds of thousands of individuals in Europe and the USA (Ware et al., 1981; Katsouyanni et al., 1997; Dominici et al., 2003; Samoli et al., 2008; Fattore et al., 2011; Ghanbari Ghozikali et al., 2016). The negative effect of particulate matters, especially those with aerodynamic diameter of less than $2.5 \mu \mathrm{g}\left(\mathrm{PM}_{2.5}\right)$, on human health was determined not only at high concentrations but also at low concentrations, and such matters are linked to respiratory morbidity and mortality (Pope et al., 1995; Sun et al., 2004; Bell et al., 2006; Downs et al., 2007; Hvidtfeldt et al., 2019; Sarkodie et al., 2019). According to previous epidemiological studies, $\mathrm{PM}_{2.5}$ has a stronger impact in terms of premature deaths and potential health effects from prolonged exposure compared to $\mathrm{PM}_{10}$ (Hamanaka and Mutlu, 2018; Kihal-Talantikite et al., 2019). It was reported that particulate matter of this size bypasses the defence mechanisms of the upper respiratory tract and affects all body systems by 
first reaching the pulmonary alveoli and then the systemic circulation (Lee et al., 2014).

One of the important risk factors for particularly lung cancer (Vena, 1982; Raaschou-Nielsen et al., 2016), stroke (Hong et al., 2002; Tian et al., 2018), type II diabetes (Rao et al., 2015; Renzi et al., 2018; Liu et al., 2019) and cardiovascular diseases (Yamamoto et al., 2014; Abdollahnejad et al., 2017; Rajagopalan et al., 2018; Lelieveld et al., 2019 ) is air pollution. The risk factor of air pollution varies at different levels of socio-economic development. For example, urban air pollution poses a greater risk factor in middle-income countries compared to high-income countries because significant improvements have been achieved in high-income countries in terms of controlling this risk with public health policies (WHO, 2009). Current calculations attribute 7 million premature deaths around the world to air pollution, and approximately 4.2 million of these result from outdoor air pollution (WHO, 2021). The economic cost of premature deaths attributed to outdoor particulate matter pollution and indoor air pollution to the European Nation in 2010 was approximately 1.5 trillion dollars (Prüss-Üstün et al., 2016). In a study conducted by the WHO on deaths attributed to outdoor air pollution for the year 2012, it was reported that approximately $36 \%$ of the deaths resulted from stroke while this rate was $36 \%$ for ischemic heart diseases, $14 \%$ for lung cancer, $8 \%$ for chronic obstructive lung diseases and $6 \%$ for acute lower respiratory tract infections (WHO, 2016a).

Findings obtained from epidemiological studies show that exposure to air pollution is essentially related to five diseases depending on the age group. These can be listed as (i) acute low respiratory infections (ALRI) in young children, (ii) cerebrovascular diseases (stroke) in adults, (iii) ischaemic heart diseases (IHD) in adults, (iv) chronic obstructive pulmonary disease (COPD) in adults and (v) lung cancer in adults (WHO, 2016c). Various epidemiological studies determined a relationship between the daily increase in suspended particulate matter concentration and the increase in mortality rate, while also revealing the relationship between mortality and the number of hospitalizations due to respiratory and cardiovascular diseases (Miri et al., 2016).

For Turkey, which is a party to the SDGs, the Marmara Region is the most significant geographical region in terms of both urban and industrial activities. While the six metropolitan municipalities surrounding the Sea of Marmara host some of the most important industrial production points in Turkey, they also being among the settlements with the highest urbanization rate and population density. When examined in terms of land cover, while the rate of artificial areas in Turkey is $1.9 \%$, it corresponds to $4.8 \%$ in the Marmara Region, which has 11 cities. Artificial areas have also a rate of $6.3 \%$ in the 6 metropolitan cities included in the research. Artificial areas are composed of 4 components that can be sources of air pollution: urban fabric; industrial, commercial and transport units; mine, dump and construction sites; artificial non-agricultural vegetated areas. For this reason, while the Marmara Region has a more intense urban and industrial activity compared to the general of Turkey, this activity is higher in the cities within the scope of the research compared to the Marmara Region in general. Land cover distribution is considered a representative parameter in terms of population density, urbanization and industrialization (EEA, 2018b). According to the 2020 census data, the population density in Turkey has been recorded as 109 , while the city with the highest population density was recorded as Istanbul $(2,976)$ and the second province was Kocaeli $(553)$. Of the approximately 25.7 million people living in the Marmara Region, 22.9 live in cities which are above the Turkey population density. The population density of only Balıkesir (87) among the cities included in the research is below the Turkey average (TURKSTAT, 2021). Despite the fact that air pollution resulting from the use of coal for heating purposes in the Marmara Region has decreased over the years, the increase in population-related urban activities and industrial activities keeps air pollution among significant health threats.

Especially in recent years, many studies have been carried out on the health effects of air pollution in Turkey. These studies are generally presented using 1-year data on either a provincial or national basis. While there are some studies, as did Akyuz et al. (2020), include national comparisons, on the other hand, there are some studies (Gül et al., 2011; Çapraz et al., 2017) examine hospital admissions for diseases attributed air pollution. In addition, mortality and morbidity studies on the basis of air pollution sources have also been conducted in Turkey (Ara Aksoy et al., 2021). As modelled in the research conducted by Ara Aksoy et al. (2021), it is evaluated that administrative regulations encouraging the use of electric or hybrid vehicles instead of those using fossil fuels can provide up to $41 \%$ reductions in $\mathrm{PM}_{2.5}$ concentrations. Our study, on the other hand, compares the metropolitan cities of the Marmara Region, which is the most dynamic region of Turkey in terms of economic and urban mobility, with 4-year data. This comparison is unique in that it calculates premature deaths from all causes caused by air pollution at the regional level. In the present study, the change in mortality rate attributed to particulate matter air pollution in the Marmara Region over the years (2016-2019) has been examined and the cities were compared. In this comparison, it was decided to use the AirQ + model proposed by the WHO. The results obtained were compared with those gathered using the same model for different cities around the world, and interpreted. 


\section{Materials and methods}

In the present study on the average level of air pollution and the impact of this level on human health, the years 2016, 2017, 2018 and 2019 are evaluated. 2020 data have been excluded in order to avoid the misleading interferences of the impact of the COVID-19 pandemic on air quality. The flow diagram in Fig. 1 shows the steps followed in the study and the path followed in the assessment of the findings.

\section{Study area and air quality monitoring stations}

The Marmara Region consists of 11 cities located around the Sea of Marmara in the northwest of Turkey where approximately $31 \%$ of the country's population lives. There are 6 metropolitan municipalities in the Marmara Region where urban and industrial activity is relatively denser. By population, these cities can be listed as Istanbul $(15,462,452)$, Bursa $(3,101,833)$, Kocaeli $(1,997,258)$, Balıkesir $(1,240,285)$, Tekirdağ $(1,081,065)$ and Sakarya $(1,042,649)$ (TURKSTAT, 2021). The surface area of the 6 metropolitan municipalities selected as the study area is approximately $45,000 \mathrm{~km}^{2}$ and these cities represent the region as they account for approximately $68 \%$ of its terrestrial area. Air quality measurements in Turkey are conducted regionally by the Clean Air Centres affiliated with the Ministry of Environment and Urbanization. As of 2019 , there are 5 air quality measurement stations affiliated with the Marmara Clean Air Center in Balıkesir, 6 in Bursa, 12 in Istanbul, 12 in Kocaeli, 4 in Sakarya and 5 in Tekirdağ. Figure 2 shows the location of the study area and the air quality measurement stations located in the area.

The data of the stations that made measurements for more than $75 \%$ of the days in a calendar year were regarded as suitable within the scope of the present study. The daily average $\mathrm{PM}_{2.5}$ concentrations of the stations that met these conditions were averaged, and the annual average $\mathrm{PM}_{2.5}$ concentration was calculated by considering all of the resulting daily average $\mathrm{PM}_{2.5}$ concentrations of each city. Within the scope of the present study, the $\mathrm{PM}_{2.5}$ concentrations for the air quality measurement stations where no $\mathrm{PM}_{2.5}$ measurement was performed were calculated by converting the $\mathrm{PM}_{10}$ concentrations measured using the conversion coefficient (the conversion coefficient specified for Turkey by the WHO is 0.666128 ). Table 1 shows the number of stations that performed direct $\mathrm{PM}_{2.5}$ measurements in the cities included in the present study, and the number of stations where the $\mathrm{PM}_{2.5}$ concentration was calculated by converting $\mathrm{PM}_{10}$, by years. Since it was considered that the outliers did not manipulate the mean measurement values, it was decided to keep these values in the data set.

Fig. 1 Flow diagram of the study 
Fig. 2 Study area and locations of air quality stations

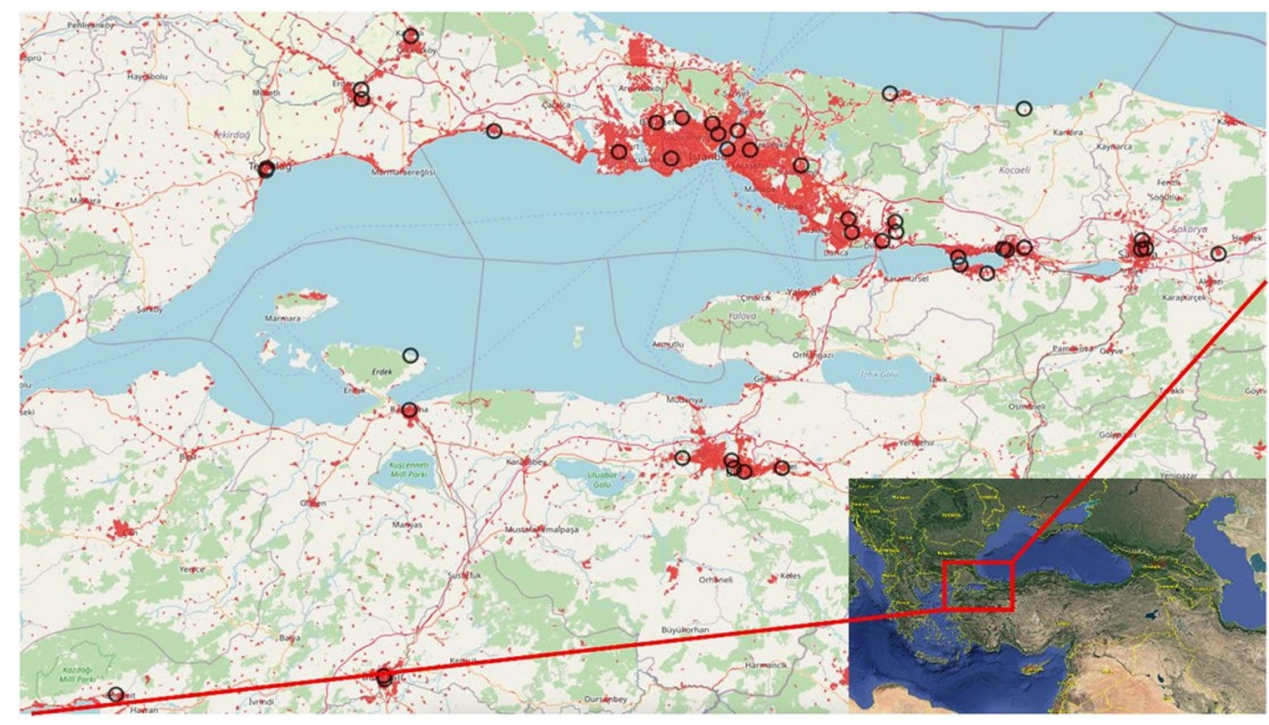

Table 1 Number of stations for measured and converted $\mathrm{PM}_{2.5}$ concentrations

\begin{tabular}{|c|c|c|c|c|c|c|c|c|}
\hline \multirow[t]{2}{*}{ Cities } & \multicolumn{2}{|l|}{2016} & \multicolumn{2}{|l|}{2017} & \multicolumn{2}{|l|}{2018} & \multicolumn{2}{|l|}{2019} \\
\hline & Direct $\mathrm{PM}_{2.5}$ & $\begin{array}{l}\text { Converted } \\
\mathrm{PM}_{2.5}\end{array}$ & Direct $\mathrm{PM}_{2.5}$ & $\begin{array}{l}\text { Converted } \\
\mathrm{PM}_{2.5}\end{array}$ & Direct $\mathrm{PM}_{2.5}$ & $\begin{array}{l}\text { Converted } \\
\mathrm{PM}_{2.5}\end{array}$ & Direct $\mathrm{PM}_{2.5}$ & $\begin{array}{l}\text { Con- } \\
\text { verted } \\
\mathrm{PM}_{2.5}\end{array}$ \\
\hline Balıkesir & 0 & 2 & 0 & 2 & 0 & 4 & 0 & 5 \\
\hline Bursa & 1 & 4 & 1 & 4 & 1 & 3 & 3 & 3 \\
\hline Istanbul & 3 & 7 & 2 & 8 & 3 & 7 & 4 & 8 \\
\hline Kocaeli & 2 & 7 & 2 & 7 & 3 & 8 & 5 & 6 \\
\hline Sakarya & 1 & 2 & 1 & 2 & 2 & 2 & 3 & 1 \\
\hline Tekirdağ & 1 & 2 & 1 & 2 & 2 & 2 & 3 & 1 \\
\hline
\end{tabular}

\section{Age-specific mortality rate}

Crude death rate (CDR) is defined as the number of deaths per 100,000 of the population in year (UN, 1991, 2001, 2021; WHO, 2016c). In the present study, the multi-year natural death rates for the cities were calculated to cover the period between 2009 and 2018. Deaths that could not technically be associated with air pollution, such as traffic accidents, murders and suicides, were not included in the total number of deaths (ICD, 2014). Age-specific mortality rates and statistics related to the causes of death were obtained from the Turkish Statistical Institute by city.

Formula 1 is used to calculate the age-specific mortality rate (ASMR) for adult individuals aged over 30 in each city.

$\operatorname{ASMR}=\frac{\mathrm{N}}{\mathrm{P}} \times 100,000$

For this calculation, the age-specific mortality rate statistics published by the Turkish Statistical Institute and the Address-Based Population Registration System were used. $N$ represents the number of natural deaths over the age of 30 while $P$ represents the population in the same age group. It was acknowledged that all individuals aged over 30 were exposed to the average level of the measured or converted $\mathrm{PM}_{2.5}$ concentrations.

\section{Air Q model and calculation of mortality rate attributed air pollution}

Version 2.0 of the AirQ + software, which was developed by the World Health Organization (WHO) Regional Office for Europe and the Bonn Office of the European Centre for Environment \& Human Health to calculate the mortality and morbidity of air pollution at a given settlement with reference to the General Principles of Health Risk Assessment of Air Pollution (WHO, 2016b), was used in the present study. Using AirQ +, the number of deaths attributed to long-term $\mathrm{PM}_{2.5}$ exposure exceeding the ambient air level of $10 \mu \mathrm{g} / \mathrm{m}^{3}$ as specified in air quality guidelines was calculated. 
Table 2 Descriptive statistics parameters for $\mathrm{PM}_{2.5}$ concentrations of cities by year

\begin{tabular}{|c|c|c|c|c|c|c|}
\hline \multirow[t]{2}{*}{ Cities } & \multirow[t]{2}{*}{ Years } & \multirow[t]{2}{*}{ Mean \pm SD } & \multirow[t]{2}{*}{ Median (IQR) } & \multirow[t]{2}{*}{ Min; Max } & \multicolumn{2}{|c|}{ Test statistics } \\
\hline & & & & & $F$ & $p$ \\
\hline \multirow[t]{4}{*}{ Balıkesir } & 2016 & $28.58 \pm 14.06$ & $25.11(14.29)$ & $9.46 ; 130.88$ & 29.864 & $<0.001$ \\
\hline & 2017 & $35.97 \pm 19.57$ & $29.83(19.02)$ & $10.71 ; 115.88$ & & \\
\hline & 2018 & $30.65 \pm 16.55$ & $25.73(13.77)$ & $7.94 ; 116.15$ & & \\
\hline & 2019 & $25.84 \pm 13.68$ & $21.31(16.02)$ & $7.27 ; 83.07$ & & \\
\hline \multirow[t]{4}{*}{ Bursa } & 2016 & $45.51 \pm 28.13$ & $36.46(27.67)$ & $11.25 ; 183.56$ & 60.064 & $<0.001$ \\
\hline & 2017 & $48.31 \pm 22.19$ & $43.37(30.00)$ & $16.02 ; 126.16$ & & \\
\hline & 2018 & $43.79 \pm 22.07$ & $36.29(25.30)$ & $10.22 ; 144.05$ & & \\
\hline & 2019 & $30.17 \pm 16.72$ & $24.47(19.56)$ & $7.72 ; 93.68$ & & \\
\hline \multirow[t]{4}{*}{ Istanbul } & 2016 & $27.57 \pm 13.95$ & $24.05(14.72)$ & $9.92 ; 147.85$ & 14.691 & $<0.001$ \\
\hline & 2017 & $30.99 \pm 12.73$ & $28.16(15.36)$ & $11.07 ; 87.29$ & & \\
\hline & 2018 & $27.60 \pm 12.12$ & $24.41(11.48)$ & $8.84 ; 78.76$ & & \\
\hline & 2019 & $25.25 \pm 11.33$ & 22.15 (11.90) & $8.52 ; 71.65$ & & \\
\hline \multirow[t]{4}{*}{ Kocaeli } & 2016 & $26.75 \pm 13.87$ & $22.95(15.52)$ & $6.59 ; 136.41$ & 44.478 & $<0.001$ \\
\hline & 2017 & $30.86 \pm 14.95$ & 27.53 (19.79) & $8.78 ; 81.41$ & & \\
\hline & 2018 & $26.49 \pm 12.63$ & 23.35 (13.49) & $5.54 ; 81.16$ & & \\
\hline & 2019 & $20.70 \pm 10.03$ & $17.75(13.02)$ & $5.05 ; 55.52$ & & \\
\hline \multirow[t]{4}{*}{ Sakarya } & 2016 & $39.10 \pm 21.83$ & $32.67(23.85)$ & $10.92 ; 142.40$ & 41.200 & $<0.001$ \\
\hline & 2017 & $40.58 \pm 19.96$ & $35.04(20.19)$ & $13.65 ; 121.69$ & & \\
\hline & 2018 & $38.96 \pm 17.75$ & $32.76(19.54)$ & $11.59 ; 118.85$ & & \\
\hline & 2019 & $29.09 \pm 15.36$ & $24.22(17.20)$ & $9.78 ; 95.40$ & & \\
\hline \multirow[t]{4}{*}{ Tekirdağ } & 2016 & $46.53 \pm 18.29$ & $43.42(21.93)$ & $14.77 ; 139.48$ & 295.427 & $<0.001$ \\
\hline & 2017 & $40.02 \pm 16.24$ & $36.73(20.93)$ & $11.59 ; 114.30$ & & \\
\hline & 2018 & $23.17 \pm 9.97$ & $20.81(11.16)$ & $4.37 ; 57.11$ & & \\
\hline & 2019 & $22.46 \pm 9.67$ & $19.99(9.46)$ & $9.34 ; 63.88$ & & \\
\hline
\end{tabular}

The integrated exposure-response (IER) function is used in the prediction of the burden of disease attributed to long-term exposure to $\mathrm{PM}_{2.5}$ in ambient air (Burnett et al., 2014). Despite the presence of certain limitations, the IER approach provides a beneficial framework to evaluate the consistency of findings and estimate the burden of disease attributed to air pollution (Pope et al., 2018). The AirQ + tool was selected as it uses this function, which enables the effects of air pollution originating from different sources to be evaluated together.

The measurement of the health effects of exposure to air-pollutant materials is based on the concept of attributable proportion (AP) and the calculation of years of life loss (YLL). AP, i.e. the fraction of the health outcome and exposure of a specific population within a certain time period, can be calculated using Formula 2 (Ezzati et al., 2002):

$\mathrm{AP}=\frac{\sum\{[\mathrm{RR}(\mathrm{c})-1] \times \mathrm{P}(\mathrm{c})\}}{\sum[\mathrm{RR}(\mathrm{c}) \times \mathrm{P}(\mathrm{c})]}$

Within this equation, $R R(c)$ represents the relative risk for the health outcome of exposure in category $c$ while $\mathrm{P}(\mathrm{c})$ represents the population rate in category $c$ of exposure.
Relative risk (RR) is a function used to predict the size of the relationship between exposure and disease. Relative risks originating from air pollution are generally modelled with loglinear function (Formula 3) (Ezzati et al., 2002; Lim et al., 2012).

$R R=e^{(\alpha+\beta X)} / e^{\left(\alpha+\beta X_{0}\right)}=e^{\left[\beta\left(X-X_{0}\right)\right]}$

In the equation, $X$ represents the pollutant concentration in $\mu \mathrm{g} / \mathrm{m}^{3} . X_{0}$ shows the cut-off or counterfactual concentration. In the present study, the annual average cut-off value of $10 \mu \mathrm{g} /$ $\mathrm{m}^{3}$ (as specified in the WHO air quality guidelines) was used for $X_{0}$ in the AirQ+ model. Finally, $\beta$ represents the change in relative risk (RR) for a change of one unit at a concentration of $X$.

For all-cause mortality, the AirQ+model takes the metaanalysis of 13 cohort studies conducted by Hoek et al. (2013) as reference and regards the all-cause mortality as 1.062 (95\% CI: 1.040-1.083) at a confidence interval (CI) of 95\% (Hoek et al., 2013; Héroux et al., 2015). 


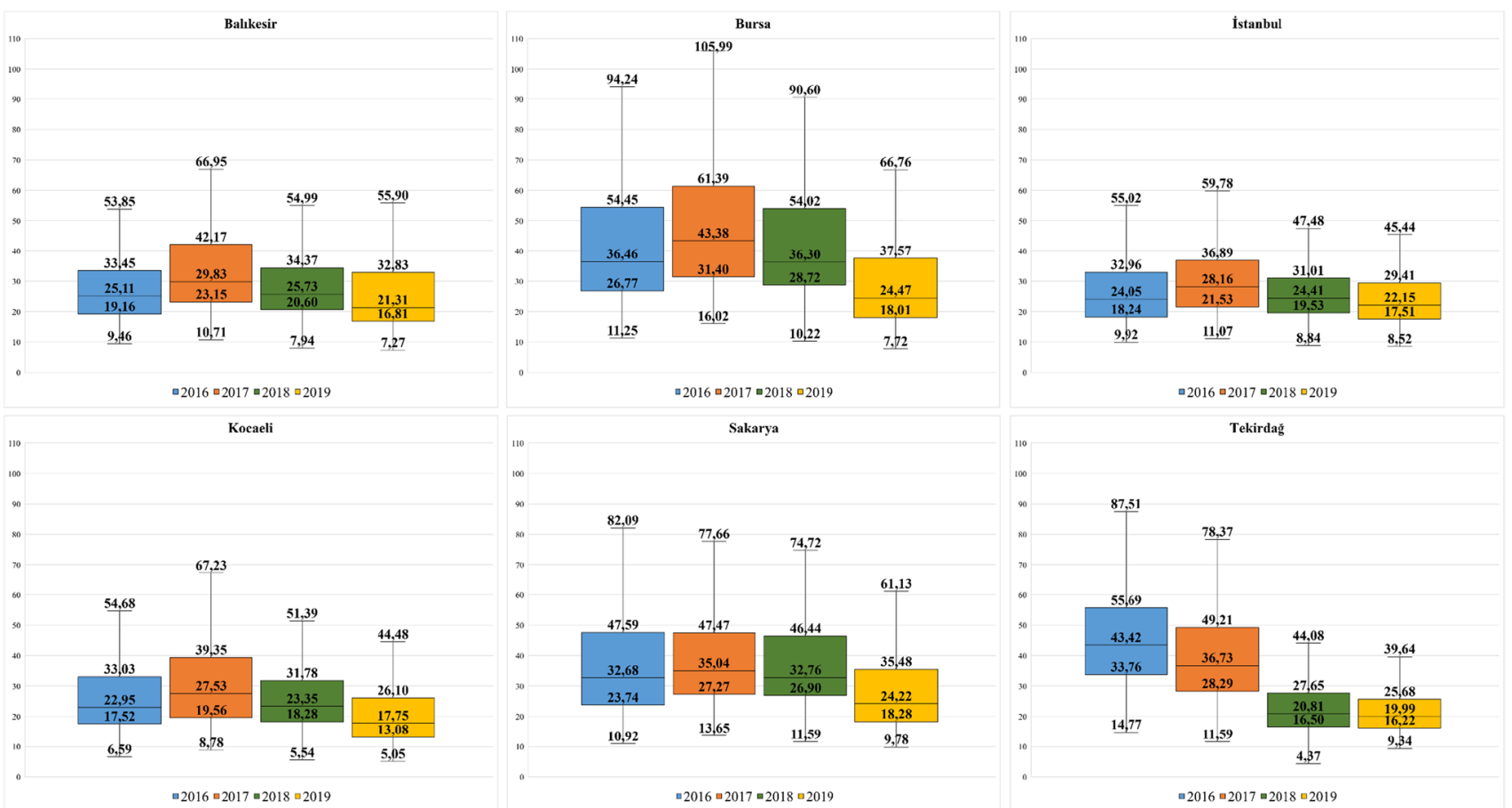

Fig. 3 Descriptive statistics values of daily average $\mathrm{PM}_{2.5}$ measurements during the year

\section{Results and discussion}

\section{Evaluation of air quality measurements}

In the cities included in the present study, data was obtained from a total of 32 stations in 2016 while this number was 42 in 2019. Table 2 shows the annual $\mathrm{PM}_{2.5}$ concentrations recorded in the cities and the descriptive statistics parameters mean \pm standard deviation, median and interquartile range (IQR) values.

Whether the $\mathrm{PM}_{2.5}$ concentrations of the cities differed within themselves in the times of measurement was examined using repeated measures ANOVA. According to this, a significant difference $(p<0.05)$ was detected between four temporal measurements of $\mathrm{PM}_{2.5}$ values in all cities (2016, $2017,2018,2019)$. It can be said that air quality was relatively improved in 2019 compared to the other years.

It was recorded that $68 \%$ of a total of 1,327 stations in 32 countries reporting to the European Environment Agency exceeded the annual $\mathrm{PM}_{2.5}$ concentration limit of $10 \mu \mathrm{g} / \mathrm{m}^{3}$ (as specified in WHO guidelines) in 2016. It is observed that with the exception of Iceland, Estonia, Finland, Ireland, Sweden, Switzerland, Norway, UK, Austria, Portugal and Germany, a significant portion of the countries with average $\mathrm{PM}_{2.5}$ concentrations below the limit value of $25 \mu \mathrm{g} / \mathrm{m}^{3}$ specified in the EU legislation exceeded the limit determined by the WHO (EEA, 2018a). The annual average $\mathrm{PM}_{2.5}$ limit value is included in national legislation in certain countries.
Based on this, this value was specified as $25 \mu \mathrm{g} / \mathrm{m}^{3}$ in the $\mathrm{EU}$, $8 \mu \mathrm{g} / \mathrm{m}^{3}$ in Australia, $10 \mu \mathrm{g} / \mathrm{m}^{3}$ in Canada and Japan, $12 \mu \mathrm{g} /$ $\mathrm{m}^{3}$ in the USA and Mexico, $15 \mu \mathrm{g} / \mathrm{m}^{3}$ in Ecuador, El Salvador and the Dominican Republic, $20 \mu \mathrm{g} / \mathrm{m}^{3}$ in South Africa, $15 \mu \mathrm{g} / \mathrm{m}^{3}$ in rural parts of China, $35 \mu \mathrm{g} / \mathrm{m}^{3}$ in urban parts of

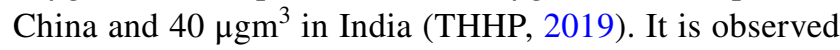
that all cities included in the present study exceeded the limit value of $10 \mu \mathrm{g} / \mathrm{m}^{3}$ specified by the WHO in each year (2016-2019). Additionally, it is observed that Balıkesir, Istanbul, Kocaeli and Tekirdağ had annual average $\mathrm{PM}_{2.5}$ concentrations at EU limits in 2019, but the annual average $\mathrm{PM}_{2.5}$ concentrations of Bursa and Sakarya were above the EU limits. It is thought that the air pollution occurring in Bursa, particularly in winter months, essentially originates from industrialization, and the significant pollution factor is coal, which is used for domestic heating and as an industrial fuel. It is known that the ring road passing through the north of the city creates traffic-related pollution based on the prevailing wind direction. The compaction of the particulate matter carried from the north through this type of wind also affects the air quality in Bursa negatively (MoEU, 2020a). Agricultural areas are located in the north of the city and the dust originating from agricultural activities is regarded as among the important factors of inner-city air pollution. The use of coal with low calorific value is the leading air pollution factor in Sakarya. In relation to this, the low air circulation in the city centre, particularly during winter months, causes pollutants to get concentrated in the low parts of the 
city. Additionally, the number of facilities that were granted environmental permits in terms of emission control was 94 in the year 2016 while this number has increased to 220 in the year 2020, which is an important fact in terms of industrial air pollution (MoEU, 2020b).

The average $\mathrm{PM}_{2.5}$ concentrations of the cities, recorded each day of the year between 2016 and 2019, were examined and Fig. 3 shows the daily concentration accumulations. In all cities, accumulations were observed in the second quarter in the daily $\mathrm{PM}_{2.5}$ concentrations recorded.

Since the cities included in the present study were subjected to multiple comparisons within themselves (4 years), whether there was a statistically significant difference in pairwise comparisons between the years (two years) was examined using the Bonferroni correction. According to this, significant differences were determined in all years except the dual years of 2016-2018 in Balıkesir; 2016-2017 and 2016-2018 in Bursa; 2016-2018 in Istanbul; 2016-2018 in Kocaeli; 2016-2017, 2016-2018 and 2017-2018 in Sakarya; and 2018-2019 in Tekirdağ. Table 3 shows the Bonferroni correction results regarding the pairwise comparisons of the cities' annual $\mathrm{PM}_{2.5}$ concentrations.

In the light of these determinations, it is acknowledged that the decrease in the average concentration in each city was recorded as an improvement in air quality since the difference in the dual comparisons of 2016-2019 and 2017-2019 was significant. Additionally, the decrease in the number of days in which the average $\mathrm{PM}_{2.5}$ concentration limit value of $25 \mu \mathrm{g} / \mathrm{m}^{3}$ specified by the WHO was exceeded within a calendar year is significant with the $p<0.05$ value in the 2016-2019 dual comparison according to the Bonferroni correction. Figure 4 shows the change in the number of days in which the WHO limit values were exceeded in the cities by year.

The average $\mathrm{PM}_{2.5}$ concentration values of the cities included in the present study during periods where sunny and cloudy days were common in the years 2016, 2017, 2018 and 2019 were examined using the unpaired $T$ test. September, October, November, December, January and February constituted the cloudy period while March, April, May, June, July and August were regarded as constituting the sunny period. According to this, it was observed that the annual seasonal differences between the sunny/ cloudy periods in all cities were statistically significant $(p<0.05)$ with the exception of the sunny and cloudy periods in Tekirdağ in $2018(t 1.846, p$ 0.066), and that the air quality during the sunny periods was better compared to the cloudy period. Based on this, Fig. 5 shows the seasonal differences in the sunny/cloudy periods of the cities by year.

When the change in the average $\mathrm{PM}_{2.5}$ concentrations of the cities over 48 months is examined, the result obtained is in parallel with the unpaired $T$ test performed for seasonal change. Figure 6 shows the change in the monthly average
Table 3 Bonferroni correction results of dual comparison of years

\begin{tabular}{lllllll}
\hline $\begin{array}{l}\text { Dual comparison } \\
\text { of years }\end{array}$ & Balıkesir & Bursa & Istanbul & Kocaeli & Sakarya & Tekirdăg \\
\hline $2016-2017$ & a & b & $\mathbf{a}$ & $\mathbf{a}$ & b & $\mathbf{a}$ \\
$2016-2018$ & b & b & b & b & b & $\mathbf{a}$ \\
$2016-2019$ & $\mathbf{a}$ & $\mathbf{a}$ & $\mathbf{a}$ & $\mathbf{a}$ & $\mathbf{a}$ & $\mathbf{a}$ \\
$2017-2018$ & $\mathbf{a}$ & $\mathbf{a}$ & $\mathbf{a}$ & $\mathbf{a}$ & $\mathrm{b}$ & $\mathbf{a}$ \\
$2017-2019$ & $\mathbf{a}$ & $\mathbf{a}$ & $\mathbf{a}$ & $\mathbf{a}$ & $\mathbf{a}$ & $\mathbf{a}$ \\
$2018-2019$ & $\mathbf{a}$ & $\mathbf{a}$ & $\mathbf{a}$ & $\mathbf{a}$ & $\mathbf{a}$ & $\mathrm{b}$ \\
\hline
\end{tabular}

a, values lower than $0.05(p<0.05)$.

b, values equal or higher than $0.05(p>0.05)$.

Fig. 4 Number of days exceeding the WHO threshold for daily average $\mathrm{PM}_{2.5}$

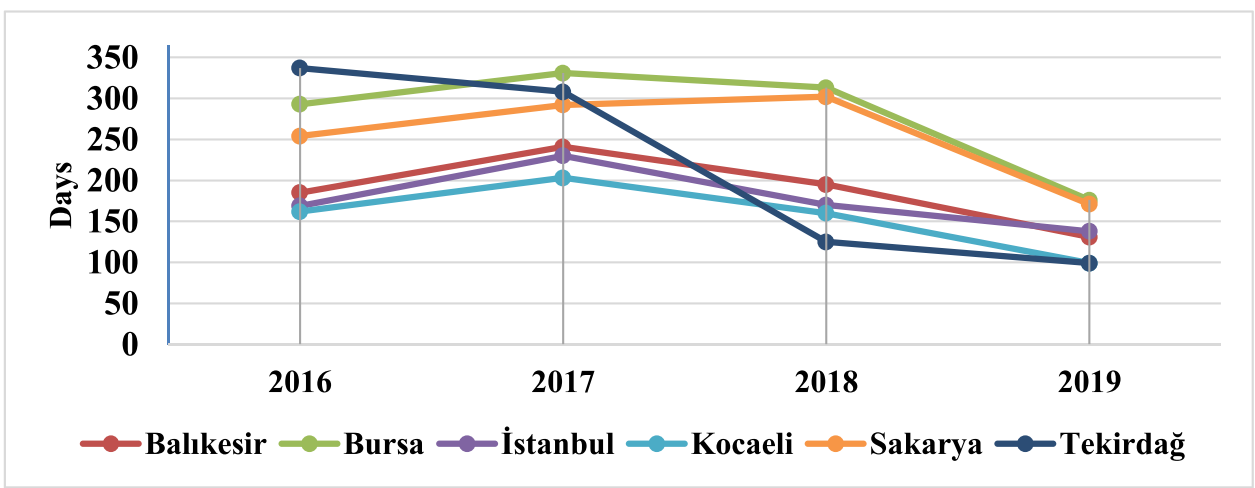


Fig. 5 Seasonal (sunny/cloudy) differences for mean $\mathrm{PM}_{2.5}$ in cities by year
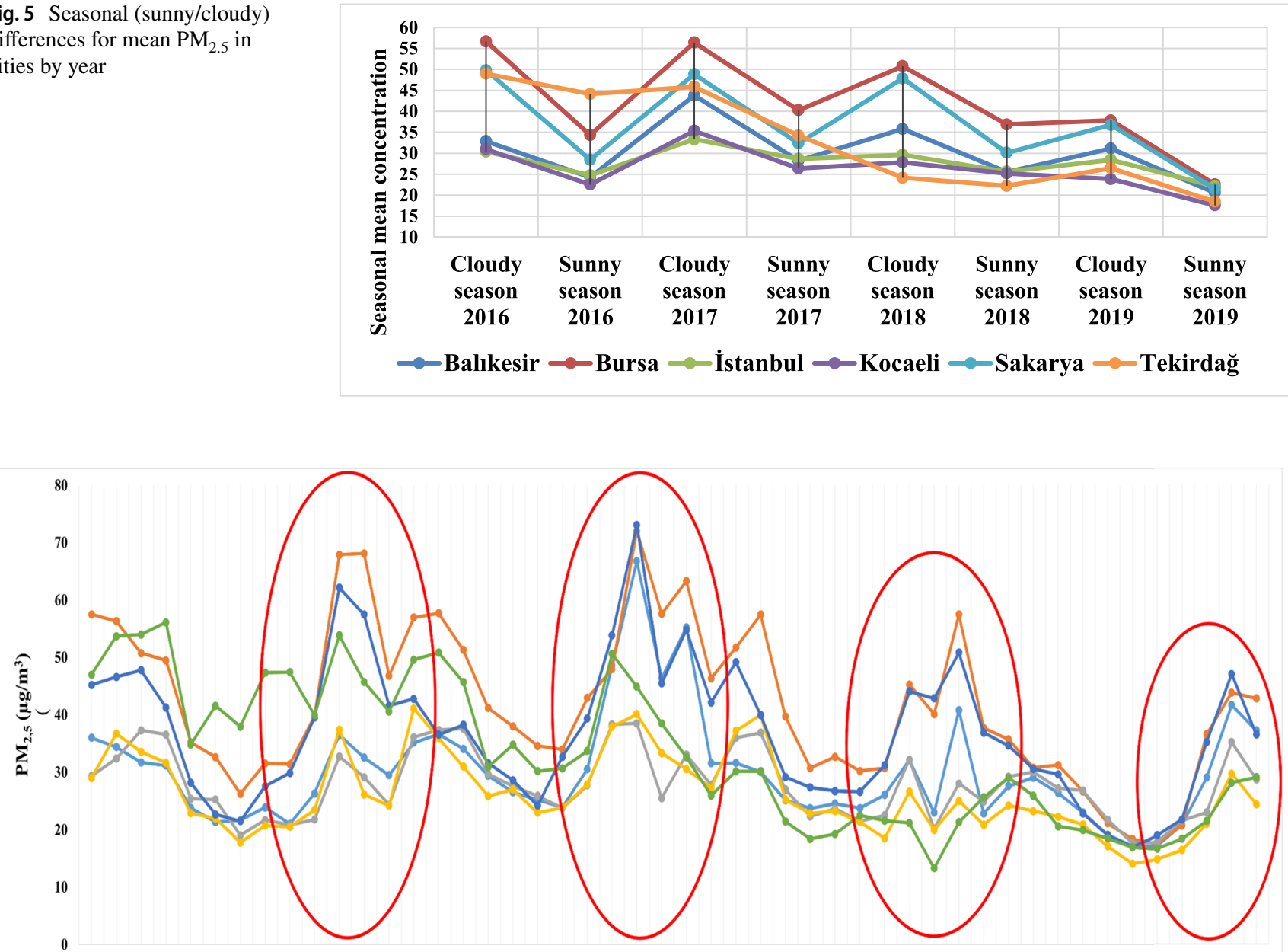

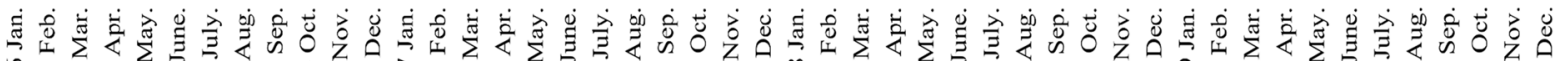

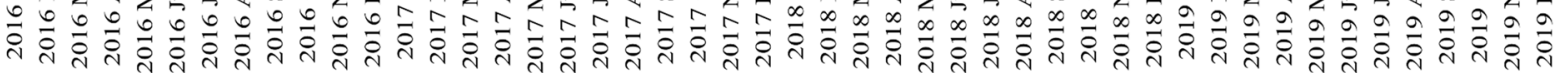

$\leadsto$ Balıesir Mean PM2,5 $\rightarrow$ Bursa Mean PM2,5 $\rightarrow$ Istanbul Mean PM2,5 $\multimap$ Kocaeli Mean PM2,5 $\rightarrow$ Sakarya Mean PM2,5 $\rightarrow$ Tekirdağ Mean PM2,5

Fig. 6 Monthly changes of mean $\mathrm{PM}_{2.5}$ concentrations through 2016-2019 years

$\mathrm{PM}_{2.5}$ values of the cities recorded over 48 months and the increase in the $\mathrm{PM}_{2.5}$ concentration during cloudy months.

When the monthly average $\mathrm{PM}_{2.5}$ concentrations of the cities included in the present study are considered, the highest monthly average in 2016 was measured during the cloudy months while the lowest average was measured during the sunny months with the exception of Balıkesir and Tekirdağ. In 2017, the highest monthly average was measured during the cloudy months with the exception of Tekirdağ while the lowest monthly average was measured during the sunny months in all cities. In 2018, the highest monthly average was measured during the cloudy months with the exception of Istanbul and Kocaeli while the lowest monthly average was measured, once again, during the cloudy months with the exception of Bursa and Sakarya. In 2019, the highest monthly average was measured during the cloudy months while the lowest monthly average was measured during the sunny months.

Meteorological factors are important in terms of understanding the change in air pollutant concentrations and the change in their distribution. In addition to other air pollutants, the tendencies of PM are also affected by topography and meteorological variables (Rodríguez et al., 2016; Mohtar et al., 2018; Liang and Gong, 2020). In the study conducted by Bodor et al. (2020) in the Transylvania region of Romania, the highest monthly average PM concentration was recorded in February at four times the annual average. Additionally, a negative correlation was observed between PM and temperature (Bodor et al., 2020). Onat et al. (2019) have obtained a correlation between traffic-related air pollutant concentrations and seasonal changes in Istanbul. Also, Çapraz et al. (2016) 
have revealed that air pollutants are effective over long distances with the effect of wind. In addition, in the study conducted in Edirne, Istanbul, Kocaeli, Tekirdağ and Yalova (some cities in Marmara Region) by Bozkurt (2018), it was revealed that the concentrations of particulate matter $\left(\mathrm{PM}_{10}\right.$ and $\left.\mathrm{PM}_{2.5}\right)$ were higher in inverse proportion to the temperature in the winter months.

It was revealed by Cichowicz et al. (2017) that air pollutant concentrations in Poland are high during the winter months and heating seasons and low during the summer months. Mohtar et al. (2018) revealed that PM concentrations in Malaysia were high during these seasons in relation to burning biomass and coal with low calorific value. In the present study, statistically significant differences were determined in the average $\mathrm{PM}_{2.5}$ concentrations during the season categories by the number of sunny and cloudy days, and it was revealed that PM-related air pollution was highest in all cities during November, December, January and February.

\section{Natural mortality rates and air pollution attributable deaths}

In the cities included in the present study, the natural mortality rates in adults aged over 30 were calculated in units of 100 thousand, taking into account all mortality cases except those in relation to external injuries and poisoning. Figure 7 shows the mortality rates in the cities.

The natural mortality rate in adults $(30+)$ during the years 2013-2014 was recorded as 876 in Paris; 871 in Santiago, the capital of Chile, during 2013-2016; and 934 in the Lombardia region of Italy during 2013-2016 (WHO, 2018). In the present study, the city with the highest mortality rate

Fig. 7 Mortality rate in cities

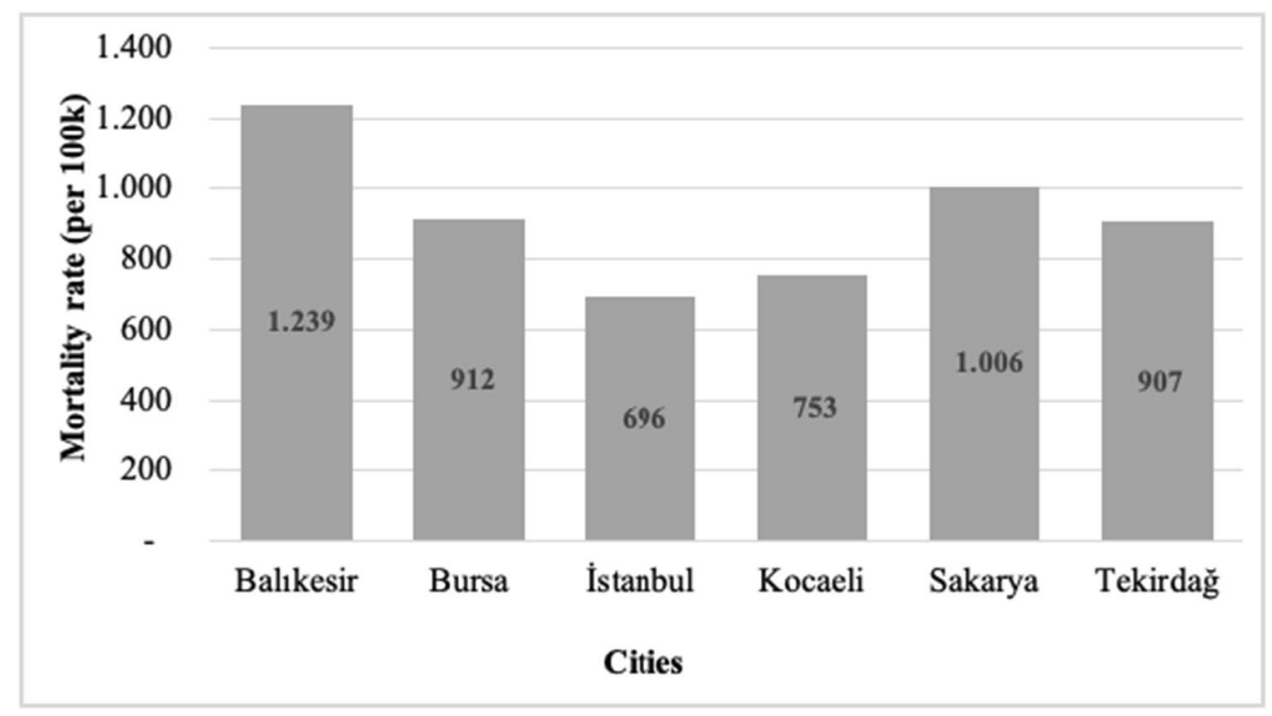

Fig. 8 Changes in the estimated attributable proportion by years

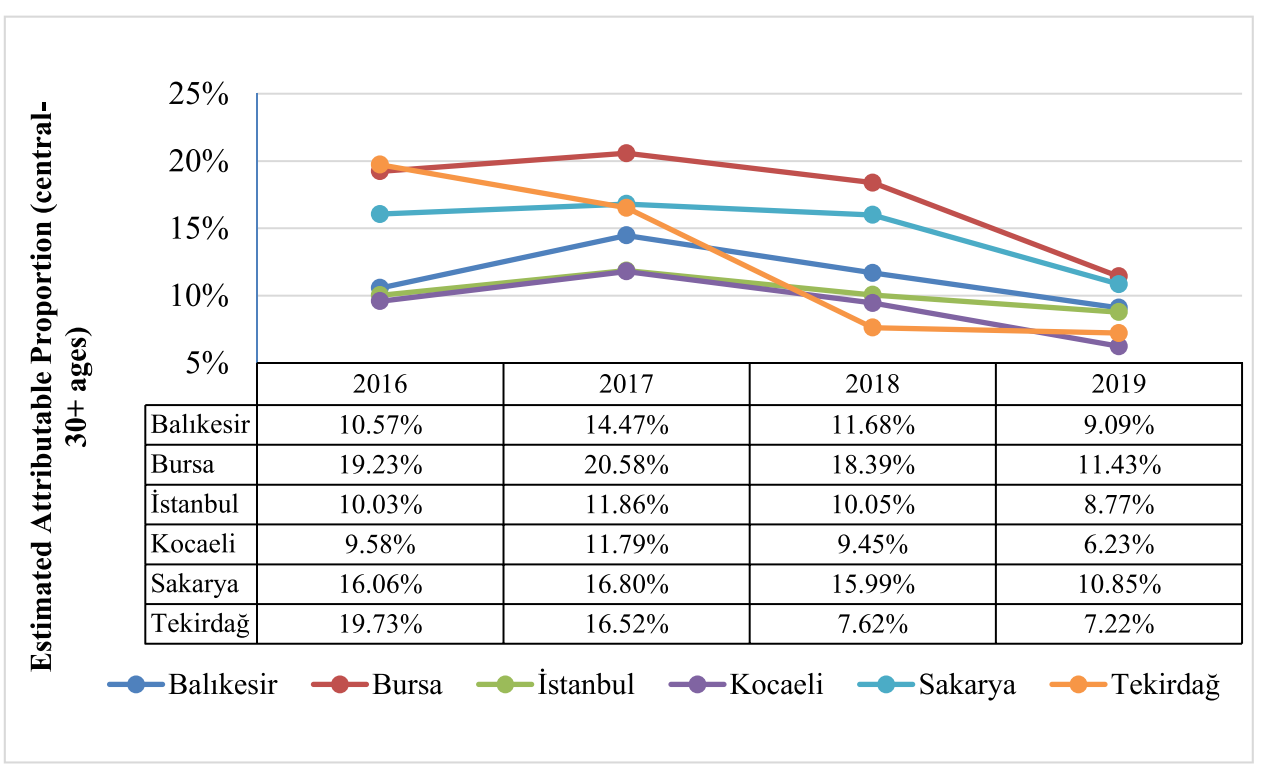


was recorded as Balıkesir while Istanbul had the lowest mortality rate.

As a fraction of the health outcome, the exposure of the population aged over 30 in the cities was calculated in the form of attributable proportion as shown in Fig. 8.

In the attributable proportion, upper and lower rates were calculated by considering a confidence interval of $95 \%$ ( $95 \% \mathrm{CI})$. Based on this, among the 4 years considered, a maximum attributable proportion of $26.32 \%$ is calculated in Bursa for the year 2017.

The AirQ model was operated with the integrated exposure-response function reference using the age-based $(30+)$ natural mortality rates and annual average $\mathrm{PM}_{2.5}$ concentrations in the cities. Based on this, Fig. 9 shows the premature deaths caused by long-term exposure to $\mathrm{PM}_{2.5}$.

In relation to the statistically significant decrease $(p<0.05)$ in $\mathrm{PM}_{2.5}$ concentrations between 2016 and 2019, it is thought that the decreasing trend in the number of premature deaths in all cities is statistically significant. It is thought that premature deaths may be prevented if air quality is improved to a point where the annual average $\mathrm{PM}_{2.5}$ concentration in cities is reduced to the annual average $\mathrm{PM}_{2.5}$ concentration threshold specified in the WHO guidelines.

Pope and Dockery (2006) revealed that an increase of $10 \mu \mathrm{g} / \mathrm{m}^{3}$ in the 24 -h average $\mathrm{PM}_{2.5}$ concentration increases the relative risk of daily cardiovascular mortality by 0.6-1.1\%. Additionally, Garcia et al. (2016) revealed a significant relationship between $\mathrm{PM}_{2.5}$ exposure and deaths caused by cardiovascular diseases, ischemic heart diseases and cardiopulmonary diseases in California. Approximately $39 \%$ of all deaths in Turkey in the years 2016, 2017 and 2018 resulted from vascular diseases. Approximately 65\% of all vascular diseases in Turkey result from ischemic heart disease and other heart diseases (TURKSTAT, 2019). In the examination performed within the scope of the present study, it was calculated that $46 \%$ of the deaths in Balıkesir resulted from vascular diseases while this rate was $44 \%$ in Bursa and $45 \%$ in Sakarya. This rate was calculated as $34 \%$ for Istanbul, $34 \%$ for Kocaeli and $40 \%$ for Tekirdağ. It is thought that the average $\mathrm{PM}_{2.5}$ concentrations measured,
Fig. 9 Changes in the estimated number of attributable cases by years
Fig. 10 Changes in the estimated attributable mortality rate by years (per $100 \mathrm{k}$ population at risk)

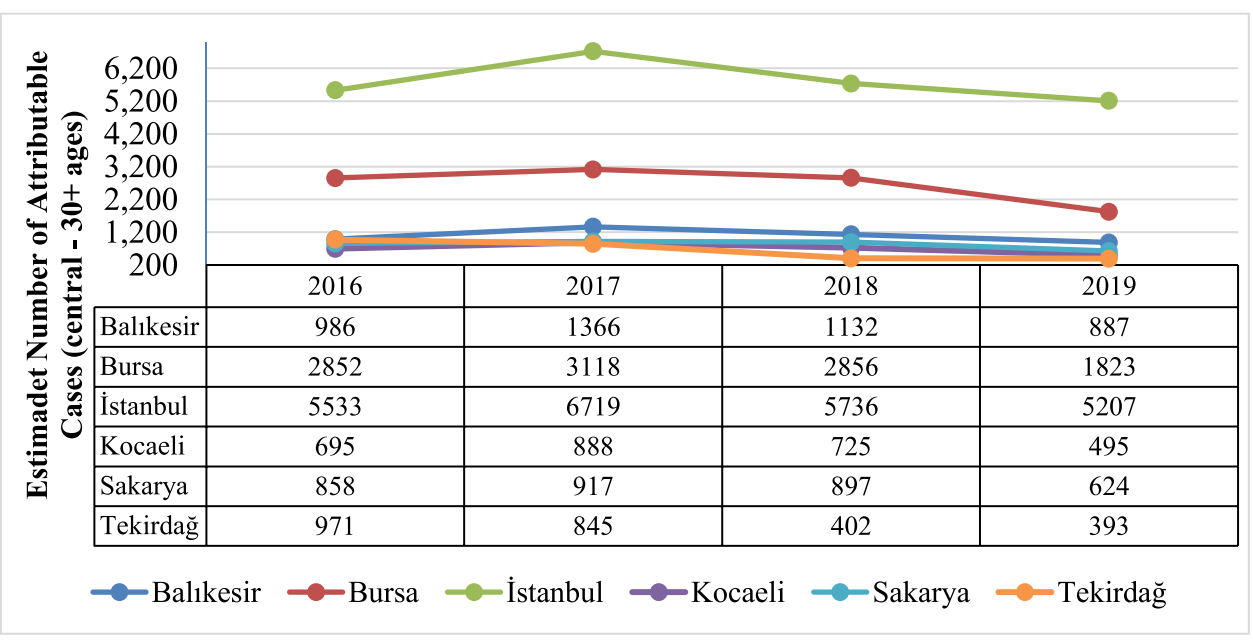

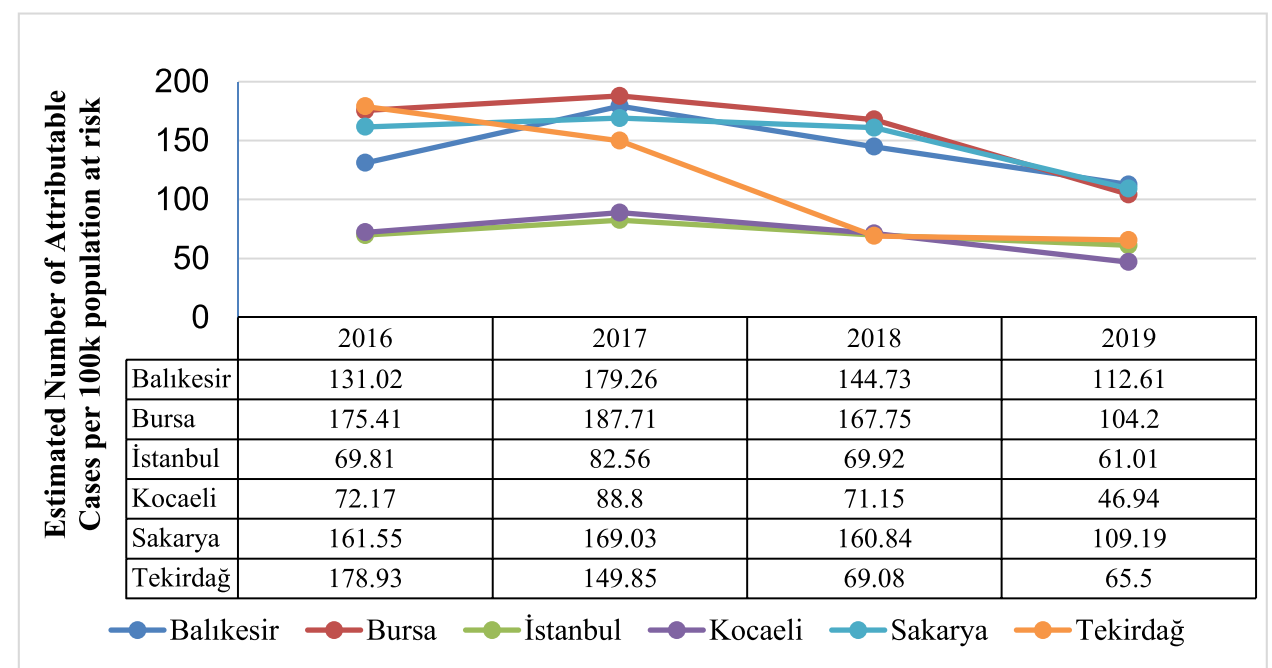


the mortality rates in the cities and national cause of death statistics are in a significant relationship.

Figure 10 shows the mortality rate (per 100 thousand) of preventable premature deaths in similar to attributable proportion. This indicator is of importance as it allows for a depopulated assessment on the health effects of air pollution. Although there was a decrease in the mortality rates in Bursa, Balıkesir and Sakarya between 2016 and 2019, it is observed that mortality rate in these cities is clearly higher compared to other cities.

In addition to the significant decrease $(p<0.001)$ in the mortality rate in Tekirdag from 2016 to 2019 , it is also acknowledged that the change between 2017 and 2018 is statistically significant $(p<0.001)$ and very apparent. Additionally, Istanbul and Kocaeli had a very low mortality rate compared to the other four cities in 2016, with a steady decrease $(p<0.05)$ up to 2019 . The dual comparison results regarding the $\mathrm{PM}_{2.5}$ value in the cities were found to be statistically significant $(p<0.05)$. Based on this significant finding, the $\mathrm{PM}_{2.5}$ values of the cities differ over the years. Only Istanbul and Kocaeli had similar $\mathrm{PM}_{2.5}$ values over the years $(p=0.493>0.05)$.

In a study conducted in 11 of the largest cities in Poland, which is the country with the highest annual average $\mathrm{PM}_{2.5}$ concentration among European Union countries, it was reported that the annual average $\mathrm{PM}_{2.5}$ concentration ranged between 14.3 and $52.5 \mu \mathrm{g} / \mathrm{m}^{3}$. The number of deaths attributed to long-term exposure to $\mathrm{PM}_{2.5}$ concentration was estimated to be 9.6 to 22.8 of every 100,000 lung cancer deaths and 48.6 to 136.6 in cases resulting from heart and lung diseases (Badyda et al., 2017). It is estimated that in 25 cities in Iran where $\mathrm{PM}_{2.5}$ pollution is common, the annual average $\mathrm{PM}_{2.5}$ concentrations are 1.5-6.1 times higher than the WHO threshold value and, consequently, 13.321 of all annual deaths recorded in these cities are classified as premature death attributed to air pollution (Hadei et al., 2020). In the present study, a decrease was observed in the overall natural mortality rates between the years 2016 and 2019. In 2019, the cases in Balıkesir, Bursa and Sakarya were calculated as above 100 (per 100 thousand), higher than Istanbul, Kocaeli and Tekirdağ.

The impact of sharp increases and decreases in air pollutant concentrations on morbidity and mortality has been subject to many studies. In the study conducted by Turner et al. (2011), it is stated that an increase of $10 \mu \mathrm{g} / \mathrm{m}^{3}$ in the $\mathrm{PM}_{2.5}$ level has caused an increase of $15-27 \%$ in deaths from cancer. Maheswaran et al. (2010) examined the impact of air pollution on post-stroke survival rates with 3.320 patients and 1.856 death cases in London. Based on this, it was revealed that an increase of $10 \mu \mathrm{g} / \mathrm{m}^{3}$ in the concentration of particulate matter with a diameter of less than $10 \mu \mathrm{m}$ increased the probability of post-stroke mortality by $52 \%$. In the study conducted by Brook et al. (2010) on the relationship between cardiovascular diseases and air pollution, it was reported that a decrease of $10 \mu \mathrm{g} / \mathrm{m}^{3}$ in $\mathrm{PM}_{2.5}$ concentrations increased life expectancy by $0.61 \pm 0.20$ years. In the study conducted by Pala et al. (2021) in all of Turkey, it was stated that 44.617 cases of premature death in 2018 could have been prevented had the air quality been at the threshold level specified by the WHO. In this context, in the present study, 11.895 (95\% CI, 7.951-15.409), 13.853 (95\% CI, 9.281-17.906), 11.748 (95\% CI, 7.838-15.243) and 9.429 (95\% CI, 6.250-12.303) premature deaths were attributed to excessive air pollution values in 2016, 2017, 2018 and 2019, respectively. It is thought that such premature deaths can be prevented if a level of air quality that is in accordance with the WHO limits can be established. According to our study, a significant proportion of the total premature deaths attributed to air pollution in the Marmara Region (approximately 47\%) have occurred in Istanbul. Recently time series studies revealed a strong correlation between $\mathrm{PM}_{2.5}$ pollution and the risk of heart and respiratory diseases and total deaths. It is considered that there is a similar correlation for Istanbul as well (Çapraz et al., 2016).

It has been observed that the changes in the mortality rate caused by the $1 \mu \mathrm{g} / \mathrm{m}^{3}$ change in the annual average $\mathrm{PM}_{2.5}$ concentration in the cities within the scope of the research are proportional to the natural mortality rates. Accordingly, with $1 \mu \mathrm{g} / \mathrm{m}^{3}$ change in annual mean $\mathrm{PM}_{2.5}$ concentration, the mortality rate is approximately $6.57-$ unit (cases $/ 100 \mathrm{k}$ population) for Balıkesir, 4.49 for Bursa, 3.75 for Istanbul, 4.25 for Kocaeli and Sakarya. 5.11- and 4.77-unit changes were calculated for Tekirdağ. When these change factors are evaluated together with the population parameter, even $1 \mu \mathrm{g} / \mathrm{m}^{3}$ reduction in the annual average $\mathrm{PM}_{2.5}$ concentration becomes vital.

\section{Conclusion}

In the present study covering the period between 2016 and 2019 for 6 cities in the Marmara Region, premature deaths attributed to air pollution were calculated based on the $\mathrm{PM}_{2.5}$ concentrations measured, and the relationship between air quality, human health and life expectancy was focused on. In this context, the results obtained in this study should be evaluated within the framework of air quality monitoring, improving air quality and reducing the impact of air quality on health.

In order to take action both in environmental management and health management by effectively monitoring air quality, a threshold value for the $\mathrm{PM}_{2.5}$ parameter, whose effect on the health impact has been revealed by many studies, should be determined in accordance with WHO guidelines and included in national regulations. As seen in this study, although there are 42 measurement stations in 6 cities within 
the scope of the research, only 18 stations measure $\mathrm{PM}_{2.5}$ directly. Although $\mathrm{PM}_{2.5}$ estimations can be made with empirical conversion factors declared by WHO, directly measured concentrations are necessary to reach definitive results. It is considered that this requirement will only be sustainable if $\mathrm{PM}_{2.5}$ threshold values are included in national regulations. In this respect, specifying limit values for $\mathrm{PM}_{2.5}$ in the Regulation on Air Quality Assessment and Management within the framework of WHO documents and EU regulations is thought to be of importance step for the effective monitoring of its effects on human health.

It is known that almost all parameters related to air pollution originate from incineration processes, industrial activities and traffic. For this reason, it is necessary to limit the use of coal with low calorific value in order to reduce air pollution caused by heating. According to the mortality rates of the cities we obtained within the scope of this study, it is seen that the mortality rate in Balıkesir is the highest. In addition, the natural gas subscription rate in Balıkesir is around $40 \%$, which is considerably lower than the other 5 cities. The inverse relationship between the natural gas subscription rate and the lignite coal utilization rate is known. Therefore, the use of lignite coal, a significant part of which has low calorific value, should be reduced gradually in primarily Balıkesir, Sakarya and Tekirdağ. It may be effective for gas distribution firms and local governments to cooperate in providing incentives and support mechanisms for the transition from coal to natural gas.

In order to reduce traffic-based emissions in urban areas, it would be beneficial to promote walking and cycling short distances through infrastructure improvements. It would be beneficial to conduct studies towards adopting sustainable production and consumption principles with the aim of reducing industrial air pollution. These studies should be within the scope of the "National Green Deal Action Plan" published by the Ministry of Trade in 2021, focusing on the main subjects of technological developments, the sustainability of administrative sanctions and the effective use of economic tools. Additionally, providing digital communication tools that can recommend alternative routes to drivers and notify pedestrians on what time to go out in order to reduce exposure to traffic-based emissions as a public service is thought to be beneficial from many aspects. Finally, it is of importance to plan residential areas in consideration of air pollution dynamics, meteorological conditions and topographical factors.

Acknowledgements We would like to thank Mr. Emre Yaşar who supported us in checking the necessary statistical analyses within the study and the Marmara Clean Air Centre who provided the location information of the Air Quality Measurement Stations in the Marmara Region, and also, special thanks to Prof. Dr. Burcu Onat and Prof. Dr. Ülkü Alver Şahin for their valuable assessments and comments.
Author contribution ACK: literature search, study design, data acquisition, data analysis, statistical analysis, AirQ model results, manuscript preparation, corresponding author.

NS: concept, design, data interpretation, definition of intellectual content, manuscript editing, "guarantor".

Data availability The data sets generated and/or analysed during the current study are available in the Ministry of Environment and Urbanization, National Air Quality Monitoring Network repository, https:// www.havaizleme.gov.tr/, Turkish Statistical Institute, Death Statistics repository and https://biruni.tuik.gov.tr/medas/?kn=114\&locale=en.

\section{Declarations}

Ethics approval and consent to participate Not applicable.

Consent for publication Not applicable.

Competing interests The authors declare no competing interests.

\section{References}

Abdollahnejad A et al (2017) Cardiovascular, respiratory, and total mortality ascribed to $\mathrm{PM}_{10}$ and $\mathrm{PM}_{2.5}$ exposure in Isfahan, Iran. Journal of Education and Health Promotion 6(December):1-6. https://doi.org/10.4103/jehp.jehp_166_16

Akyuz E, Samavati M, Kaynak B (2020) Spatial distribution of health risks associated with $\mathrm{PM}_{2.5}$ in Turkey and Iran using satellite and ground observations. Atmos Pollut Res 11(12):2350-2360. https:// doi.org/10.1016/j.apr.2020.08.011

Ara Aksoy, S. et al. (2021) 'Mortality and morbidity costs of road traffic-based air pollution in Turkey', Journal of Transport and Health, 22(August). doi: https://doi.org/10.1016/j.jth.2021. 101142.

Badyda AJ, Grellier J, Dabrowiecki P (2017) Ambient PM $_{2.5}$ exposure and mortality due to lung cancer and cardiopulmonary diseases in Polish cities. Adv Exp Med Biol 944:9-17. https://doi.org/10. 1007/5584_2016_55

Bell ML, Peng RD, Dominici F (2006) The exposure-response curve for ozone and risk of mortality and the adequacy of current ozone regulations. Environ Health Perspect 114(4):532-536. https://doi. org/10.1289/ehp.8816

Bodor Z et al (2020) Major air pollutants seasonal variation analysis and long-range transport of PM10 in an urban environment with specific climate condition in Transylvania (Romania). Environ Sci Pollut Res 27(30):38181-38199. https://doi.org/10.1007/ s11356-020-09838-2

Bozkurt Z (2018) $\mathrm{PM}_{10}$ ve $\mathrm{PM}_{2.5}$ Boyutundaki Atmosferik Partiküllerin Bölgesel, Mevsimsel Değişimlerinin ve Meteorolojik Parametrelerle İlişkilerinin İncelenmesi. Düzce Üniversitesi Bilim Ve Teknoloji Dergisi 6(4):1305-1320. https://doi.org/10.29130/dubit ed. 428821

Brook RD et al (2010) Particulate matter air pollution and cardiovascular disease. Circulation 121(21):2331-2378. https://doi.org/10. 1161/CIR.0B013E3181DBECE1

Burnett RT et al (2014) An integrated risk function for estimating the global burden of disease attributable to ambient fine particulate matter exposure. Environ Health Perspect 122(4):397-403. https:// doi.org/10.1289/ehp.1307049

Çapraz Ö, Deniz A, Doğan N (2017) Effects of air pollution on respiratory hospital admissions in İstanbul, Turkey, 2013 to 2015. 
Chemosphere 181:544-550. https://doi.org/10.1016/j.chemo sphere.2017.04.105

Çapraz Ö, Efe B, Deniz A (2016) Study on the association between air pollution and mortality in İstanbul, 2007-2012. Atmos Pollut Res 7(1):147-154. https://doi.org/10.1016/j.apr.2015.08.006

Cichowicz R, Wielgosiński G, Fetter W (2017) Dispersion of atmospheric air pollution in summer and winter season. Environ Monit Assess 189(12):605. https://doi.org/10.1007/ s10661-017-6319-2

Dominici F et al (2003) Airborne particulate matter and mortality: timescale effects in four US cities. Am J Epidemiol 157(12):10551065. https://doi.org/10.1093/aje/kwg087

Downs SH et al (2007) Reduced exposure to PM 10 and attenuated age-related decline in lung function. N Engl J Med 357(23):2338 2347. https://doi.org/10.1056/nejmoa073625

EEA (2018a) Air quality in Europe 2018. Copenhagen. Available at: papers2://publication/ uuid/1D25F41B-C673-4FDA-AB71-CC5A2AD97FDD.

EEA (2018b) Coordination of Information on the Environment, CORINE. Available at: http://corine.tarimorman.gov.tr/corin eportal/.

Ezzati M et al (2002) Selected major risk factors and global and regional burden of disease. Lancet 360(9343):1347-1360. https:// doi.org/10.1016/S0140-6736(02)11403-6

Fattore $\mathrm{E}$ et al (2011) Human health risk in relation to air quality in two municipalities in an industrialized area of Northern Italy. Environ Res 111(8):1321-1327. https://doi.org/10.1016/j.envres.2011.06. 012

Garcia CA et al (2016) Association of long-term $\mathrm{PM}_{2.5}$ exposure with mortality using different air pollution exposure models: impacts in rural and urban California. Int J Environ Health Res 26(2):145. https://doi.org/10.1080/09603123.2015.1061113

Ghanbari Ghozikali M et al (2016) Evaluation of Chronic Obstructive Pulmonary Disease (COPD) attributed to atmospheric O3, NO2, and SO2 using Air Q Model (2011-2012 year). Environ Res 144(2016):99-105. https://doi.org/10.1016/j.envres.2015.10.030

Gül H et al (2011) Respiratory health symptoms among students exposed to different levels of air pollution in a Turkish city. Int. J. Environ. Res. Public Health 8(4):1110-1125. https://doi.org/10. 3390/ijerph8041110

Hadei $\mathrm{M}$ et al (2020) Burden of mortality attributed to $\mathrm{PM}_{2.5}$ exposure in cities of Iran; contribution of short-term pollution peaks. Atmos Environ 224:117365. https://doi.org/10.1016/j.atmosenv. 2020.117365

Hamanaka RB, Mutlu GM (2018) Particulate matter air pollution: effects on the cardiovascular system. Front Endocrinol 9:680. https://doi.org/10.3389/FENDO.2018.00680

Héroux ME et al (2015) Quantifying the health impacts of ambient air pollutants: recommendations of a WHO/Europe project. Int J Public Health 60(5):619-627. https://doi.org/10.1007/ s00038-015-0690-y

Hoek G et al (2013) Long-term air pollution exposure and cardiorespiratory mortality: a review. Environmental Health: A Global Access Science Source 12(1):43. https://doi.org/10.1186/ 1476-069X-12-43

Hong YC et al (2002) Air pollution: a new risk factor in ischemic stroke mortality. Stroke 33(9):2165-2169. https://doi.org/10.1161/ 01.STR.0000026865.52610.5B

Hvidtfeldt UA et al (2019) Long-term residential exposure to $\mathrm{PM}_{2.5}$, $\mathrm{PM}_{10}$, black carbon, $\mathrm{NO} 2$, and ozone and mortality in a Danish cohort. Environ Int 123(2):265-272. https://doi.org/10.1016/j. envint.2018.12.010

ICD (2014) Revised mortality underlying cause instructions, WHO International Statistical Classification of Diseases. Switzerland. Available at: https://icd.who.int/icd10updateplatform/PropD. aspx?prop=2109 (Accessed: 17 July 2021).
Katsouyanni K et al (1997) Short term effects of ambient sulphur dioxide and particulate matter on mortality in 12 European cities: results from time series data from the APHEA project. BMJ 314(7095):1658-1663. https://doi.org/10.1136/BMJ.314.7095. 1658

Kihal-Talantikite W et al (2019) Premature adult death and equity impact of a reduction of $\mathrm{NO}_{2}, \mathrm{PM}_{10}$, and $\mathrm{PM}_{2.5}$ levels in Parisa health impact assessment study conducted at the census block level. Int. J. Environ. Res. Public Health 16(1):38. https://doi. org/10.3390/ijerph16010038

Lee B, Kim B, Lee K (2014) Air pollution exposure and cardiovascular disease. Toxicol. Res 30(2):71-75. https://doi.org/10.5487/ TR.2014.30.2.071

Lelieveld J et al (2019) Cardiovascular disease burden from ambient air pollution in Europe reassessed using novel hazard ratio functions. Eur Heart J 40(20):1590-1596. https://doi.org/10.1093/ eurheartj/ehz135

Liang L, Gong P (2020) Urban and air pollution: a multi-city study of long-term effects of urban landscape patterns on air quality trends. Sci Rep 10(1):1-13. https://doi.org/10.1038/ s41598-020-74524-9

Lim SS et al (2012) A comparative risk assessment of burden of disease and injury attributable to 67 risk factors and risk factor clusters in 21 regions, 1990-2010: a systematic analysis for the Global Burden of Disease Study 2010. The Lancet 380(9859):2224-2260. https://doi.org/10.1016/S0140-6736(12) 61766-8

Liu F et al (2019) Associations between long-term exposure to ambient air pollution and risk of type 2 diabetes mellitus: A systematic review and meta-analysis. Environ Pollut 252:1235-1245. https:// doi.org/10.1016/j.envpol.2019.06.033

Maheswaran R et al (2010) Impact of outdoor air pollution on survival after stroke: population-based cohort study. Stroke 41(5):869-877. https://doi.org/10.1161/STROKEAHA.109.567743

Miri M et al (2016) 'Mortality and morbidity due to exposure to outdoor air pollution in Mashhad metropolis Iran the AirQ Model Approach.' Environ Res 151:451-457. https://doi.org/10.1016/j. envres.2016.07.039

MoEU (2020a) Bursa Clean Air Action Plan 2020-2024. Bursa.

MoEU (2020b) Sakarya Clean Air Action Plan 2020-2024. Sakarya.

Mohtar AAA et al (2018) Variation of major air pollutants in different seasonal conditions in an urban environment in Malaysia. Geosci Lett 5(1):21. https://doi.org/10.1186/s40562-018-0122-y

Onat B et al (2019) Determinants of exposure to ultrafine particulate matter, black carbon, and $\mathrm{PM}_{2.5}$ in common travel modes in Istanbul. Atmos. Environ 206:258-270. https://doi.org/10.1016/j.atmos env.2019.02.015

Pala K, Aykac N, Yasin Y (2021) Premature deaths attributable to long-term exposure to $\mathrm{PM}_{2.5}$ in Turkey. Environ Sci Pollut Res Int (2017) 28(37):51940-51947. https://doi.org/10.1007/ s11356-021-13923-5

Pope CA 3rd, Dockery DW (2006) Health effects of fine particulate air pollution: lines that connect. J Air WasteManag Assoc. 56(6):709-42. https://doi.org/10.1080/10473289.2006.10464485

Pope CA et al (1995) Particulate air pollution as a predictor of mortality in a prospective study of U.S. adults. Am. J. Respir. Crit. Care Med 151(3_pt_1):669-674. https://doi.org/10.1164/ajrccm/ 151.3_Pt_1.669

Pope CA, Cohen AJ, Burnett RT (2018) Cardiovascular disease and fine particulate matter lessons and limitations of an integrated exposure-response approach. Circ Res 122(12):1645-1647. https://doi.org/10.1161/CIRCRESAHA.118.312956

Prüss-Ustün, A. et al. (2016) Preventing disease through healthy environments: a global assessment of the environmental burden of disease, WHO. Geneva. Available at: www.who.int/about/licen sing/copyright_form/en/index.html. 
Raaschou-Nielsen O et al (2015) (2016) 'Particulate matter air pollution components and risk for lung cancer.' Environ Int 87:66-73. https://doi.org/10.1016/j.envint.2015.11.007

Rafaj P et al (2018) Outlook for clean air in the context of sustainable development goals. Glob Environ Chang 53(April):1-11. https:// doi.org/10.1016/j.gloenvcha.2018.08.008

Rajagopalan S, Al-Kindi SG, Brook RD (2018) Air pollution and cardiovascular disease: JACC State-of-the-Art Review. J Am Coll Cardiol 72(17):2054-2070. https://doi.org/10.1016/j.jacc.2018. 07.099

Rao X et al (2015) Air pollution as a risk factor for type 2 diabetes. Toxicol Sci 143(2):231-241. https://doi.org/10.1093/TOXSCI/ KFU250

Renzi M et al (2018) Air pollution and occurrence of type 2 diabetes in a large cohort study. Environ Int 112:68-76. https://doi.org/10. 1016/j.envint.2017.12.007

Rodríguez MC, Dupont-Courtade L, Oueslati W (2016) Air pollution and urban structure linkages: evidence from European cities. Renew Sustain Energy Rev 53:1-9. https://doi.org/10.1016/j. rser.2015.07.190

Samoli E et al (2008) Acute effects of ambient particulate matter on mortality in Europe and North America: results from the APHENA study. Environ Health Perspect 116(11):1480-1486. https://doi.org/10.1289/EHP.11345

Sarkodie SA et al (2019) Proximate determinants of particulate matter $\left(\mathrm{PM}_{2.5}\right)$ emission, mortality and life expectancy in Europe, Central Asia, Australia, Canada and the US. Sci Total Environ 683:489-497. https://doi.org/10.1016/j.scitotenv.2019.05.278

Sun Y et al (2004) The air-borne particulate pollution in Beijing - concentration, composition, distribution and sources. Atmos Environ 38(35):5991-6004. https://doi.org/10.1016/j.atmosenv.2004.07. 009

THHP (2019) Policy Note on PM 2.5 . Available at: https://www.temiz havahakki.com/pm25-politika-notu/.

Tian Y et al (2018) Association between ambient air pollution and daily hospital admissions for ischemic stroke: a nationwide time-series analysis I Enhanced Reader. PLoS Med 15(10):1-16. https://doi. org/10.1371/journal.pmed.1002668

TURKSTAT (2019) Distribution of causes of death by gender, 20092018, Turkish Statistical Institute. Available at: https://data. tuik.gov.tr/Bulten/Index?p=Olum-ve-Olum-Nedeni-Istatistik leri-2019-33710.

TURKSTAT (2021) Address Based Population Registration System Results 2020, Turkish Statistical Institute. Available at: https:// biruni.tuik.gov.tr/medas/?kn=95\&locale $=$ en (Accessed: 2 March 2021).

Turner MC et al (2011) Long-term ambient fine particulate matter air pollution and lung cancer in a large cohort of never-smokers. Am J Respir Crit Care Med 184(12):1374-1381. https://doi.org/10. 1164/RCCM.201106-10110C

UN (1991) Handbook of Vital Statistics Systems and Methods. F/35. New York: United Nations Publication. Available at: https://unsta ts.un.org/unsd/publication/SeriesF/SeriesF_35v1E.pdf.

UN (2001) Principles and Recommendations for a Vital Statistics System. ST/ESA/STA. New York: UN Department of Economic and
Social Affairs. Available at: https://unstats.un.org/unsd/demog raphic-social/Standards-and-Methods/files/Principles_and_Recom mendations/CRVS/SeriesM_19rev2-E.pdf.

UN (2021) UN Data Glossary, United Nations Statistics Division. Available at: http://data.un.org/Glossary.aspx?d=DemogG (Accessed: 18 April 2021).

Vena JE (1982) Air Pollution as a Risk Factor in Lung Cancer. Am J Epidemiol 116(1):42-56. https://doi.org/10.1093/OXFORDJOUR NALS.AJE.A113401

Ware JH et al (1981) Assessment of the health effects of atmospheric sulfur oxides and particulate matter: evidence from observational studies. Environ Health Perspect 41(October):255-276. https:// doi.org/10.1289/ehp. 8141255

WHO (2009) Global Health Risks: Mortality and Burden of Disease Attributable to Selected Major Risks. Available at: http://www. who.int/healthinfo/global_burden_disease/GlobalHealthRisks_ report_full.pdf.

WHO (2016a) Ambient air pollution: A global assessment of exposure and burden of disease. Geneva. Available at: http://marefatead yan.nashriyat.ir/node/150.

WHO (2016b) Health Risk Assessment of air pollution, WHO Regional Office for Europe. Copenhagen: World Health Organization. Available at:https://www.euro.who.int/en/health-topics/environment-and-health/air-quality/activities/airq-software-tool-forhealth-risk-assessment-of-air-pollution\%0Ahttp://www.euro.who. int/en/health-topics/environment-and-health/air-quality/activities/ airq-software-t

WHO (2016c) 'Institutional information of SDG 3.9.1. Mortality rate attributed to household and ambient air pollution'. Geneva: World Health Organization, p. 1. Available at: https://www.who.int/data/ gho/data/indicators/indicator-details/GHO/ambient-and-house hold-air-pollution-attributable-death-rate-(per-100-000-popul ation-age-standardized).

WHO (2018) 'AirQ+ software tool for health risk assessment of air pollution - information documents on Mortality'. Bonn, Germany: World Health Organization, pp. 1-6. Available at: https://www. euro.who.int/en/health-topics/environment-and-health/air-quali ty/activities/airq-software-tool-for-health-risk-assessment-ofair-pollution.

WHO (2021) Air Pollution, World Health Organization. Available at: https://www.who.int/health-topics/air-pollution\#tab=tab_1.

Yamamoto SS, Phalkey R, Malik AA (2014) A systematic review of air pollution as a risk factor for cardiovascular disease in South Asia: limited evidence from India and Pakistan. Int J Hyg Environ Health 217(2-3):133-144. https://doi.org/10.1016/J.IJHEH. 2013.08.003

Publisher's note Springer Nature remains neutral with regard to jurisdictional claims in published maps and institutional affiliations. 